\title{
Electrospun nanofiber tubes with elastomagnetic properties for biomedical use
}

\author{
V. Guarino ${ }^{1}$, G. Ausanio ${ }^{2}$, V. Iannotti ${ }^{2}$, L. Ambrosio ${ }^{1}$, L. Lanotte $^{2 *}$ \\ ${ }^{1}$ Institute of Polymers, Composites and Biomaterials (IPCB) National Research Council of Italy, \\ Mostra d'Oltremare Pad. 20, V.le J.F. Kennedy 54, I-80125 Naples, Italy \\ ${ }^{2}$ CNR-SPIN and Department of Physics 'E. Pancini', University of Naples 'Federico II', Piazzale V. Tecchio 80, \\ I-80125 Naples, Italy
}

Received 17 September 2017; accepted in revised form 27 November 2017

\begin{abstract}
Electrospinning technique has been successfully used to produce composite nanofibers combining magnetic nanoparticles with polymer matrices. Process conditions to assembly nanofibers in tubular systems, as well as their morphological and elastomagnetic properties, have been explored. A volume percentage of magnetic charge close to $30 \%$ has been achieved. The optimization of the fabrication method ensures that the particles are completely covered by a thin polymer shell, so safe-guarding bio-compatibility. In particular, the deformation induced by the direct elastomagnetic effect, applying a static or a pulsed magnetic field, has been investigated. Resultant devices exhibit good elastomagnetic stretchability at room temperature-longitudinal relative strain/exciting field $\sim 4 \cdot 10^{-3} /\left(1.5 \cdot 10^{4} \mathrm{~A} / \mathrm{m}\right)$-, thus suggesting their potential use for applications in biomedical field as magneto-active components, as well as sensors and actuators.
\end{abstract}

Keywords: nanocomposites, elastomagnetic nanofibers, electrospinning, biomedical devices

\section{Introduction}

In recent years, the growing development of both electrospinning technique and polymeric materials has significantly increased the production of hybrid, or simply composite, electrospun nanofibers embedding organic and/or inorganic fillers in order to improve their functionality for biomedical or microelectronic applications [1-6]. In particular, magnetically functionalized nanofibers (MFNs), namely polymer based fibers incorporating magnetic nanoparticles (MNPs), are attracting increasing interest due to their potential use in micro-electro-mechanical devices, magnetic recording, ferrofluids, sensors, microwave absorption [7-11] and biomedical applications - i.e. bone repair [12-14], tissue engineering [15, 16], magnetic hyperthermia [17], contrast agent and imaging techniques [18-20], controlled drug release [21] and drug delivery [22].
Despite many synthesis and fabrication methods have already been used to fabricate nanofibers, electrospinning may be currently considered as the simplest, low cost and highly feasible technology to fabricate composite nanofibers with high resolution and high production rate [23, 24]. First of all, electrospun magnetic fibers exhibit remarkable properties in terms of large specific surface area and small diameter (50$500 \mathrm{~nm}$ ) due to the high stretching of magnetically functionalized polymer solutions under the application of electrostatic forces. In MFNs fabrication, polyacrylonitrile (PAN), polystyrene (PS) or polyimide (PI) have been commonly used as polymer matrix, while iron, iron oxide, cobalt, nickel, $\mathrm{LiCoO}_{2}, \mathrm{NiCo}_{2} \mathrm{O}_{4}$, $\mathrm{NiFe}_{2} \mathrm{O}_{4}, \mathrm{Fe}-\mathrm{FeO}$ core-shell nanoparticles as magnetic fillers [11, 24-31].

Several groups have variously investigated MFNs magnetic properties and their interplay with mechanical,

$\overline{{ }^{*} \text { Corresponding author, e-mail: lanotte@fisica.unina.it }}$ (C) BME-PT 
thermal and optical response [32-36], but only partial studies about the relationships between elasticity and magnetization in similar systems have been performed [37]. On the other hand, recent studies are confirming the relevance of elastic and magnetic properties coupling for the development of new multifunctional nanocomposite materials to be used as sensors and actuators [38-40].

Therefore, the main purposes of this investigation are: (i) to optimize the fabrication of magnetic composite nanofibers in order to develop three-dimensional devices with improved direct elastomagnetic coupling; (ii) to perform a quantitative study of their elastomagnetic performance.

In detail, the optimized electrospinning process to fabricate Polycarbonate-urethanes (PCU) nanofibers tubes, including Nickel (Ni) nanoparticles, has been assessed by accurate control of local interface formed between magnetic particles and polymer matrix. After a preliminary study of the morphological properties of single fiber units and nanofiber 3D-systems, main features of MFNs tubular samples in terms of direct elastomagnetic response have been investigated by providing experimental evaluation of strain induced by a static or dynamic magnetic field.

The unique attitude of elastomagnetic MFN tubes to present reversible strain or even to oscillate under pulsed magnetic field, suggests their potential use as micro-conduits for innovative biomedical applications as stone eliminating urinary stents or antithrombus vascular grafts.

\section{Materials and methods}

\subsection{Nickel-polyurethane based fibers}

PCU are catalyzing strong interest for their biomedical use, due to recognized superior biocompatibility and attractive mechanical properties (high elongation capacity, good abrasion resistance, high flexibility, and good biocompatibility for short-term usage under wet conditions) [41, 42]. In addition to the ability to withstand harsh environments due to their strong intermolecular bonds, it is possible also to repair their vulnerability to biodegradation and hydrolysis by adding polycarbonate polyol [43], thus making them suitable for the fabrication of implantable devices (i.e. vascular grafts, bone articular joint components) [44]. Herein, PCU electrospun fibers have been optimized by customizing the electrospinning setup in order to develop nanostructured tubes.
Ni nanoparticles were chosen as filler on the basis of the following points: (i) size ranging from 20 to $100 \mathrm{~nm}(99,99 \%$ Aldrich Chemical) to assure the optimal incorporation in polymer fibers having micrometric diameter; (ii) capability to preserve considerable magnetic moment; (iii) interesting elastomagnetic response when dispersed in a polymer matrix as just reported in previous works [39, 45, 46]. These requirements are not mandatory for improving biocompatibility [47] or peculiar mechanical properties, but are really important to optimize elastomagnetic response and fiber morphology, preserving magnetization response also in comparison to iron oxides [48].

The MFNs were fabricated by using a commercially available electrospinning setup (Nanon01, MECC, Japan). At first, Corethane, (15\% w/v) was dissolved into a THF/DMF (7:3) until forming a homogeneous solution. Then, Ni nanoparticles - initially $15 \% \mathrm{v} / \mathrm{v}-$ were handily mixed to the PCU solution - ca. 20 minutes - until obtaining a homogeneous viscous solution with uniform dark aspect. The solution was placed in a $5 \mathrm{~mL}$ plastic syringe connected to an 18 Gauge needle. At the first stage, the electrospun fibers were randomly collected over a grounded aluminium sheet and the process parameters (voltage, flow rate and needle-to-collector gap) were optimized to obtain flat membranes. The filling particles percentage in the solution injected in the electrospinning syringe was progressively increased until the limit of particle/polymer solution mixing without evident precipitation: this condition was reached at $30 \%(\mathrm{v} / \mathrm{v})$, not overcoming the percolation threshold of the particles in the solution itself. This condition was mandatory to maximize magnetic charge in the deposited fibers while enabling the rotation of the particles under the action of external magnetizing fields. Then, tube shaped samples were developed by collecting fibers onto a stainless steel mandrel $-3.0 \mathrm{~mm}$ in diameter - under controlled rotation. In this case, a constant rate of $50 \mathrm{rpm}$ was used. The rod was preventively wrapped by an aluminium foil in order to facilitate the extraction procedure once the fibrous tube was formed. The electrospinning process was carried out in a vertical configuration, at $25^{\circ} \mathrm{C}$ and $50 \%$ relative humidity, and the deposition time was fixed to 30 minutes to obtain the required thickness to assure an easy removal of the membranes from the rod (Figure 1a). Different parameters were investigated to optimize 

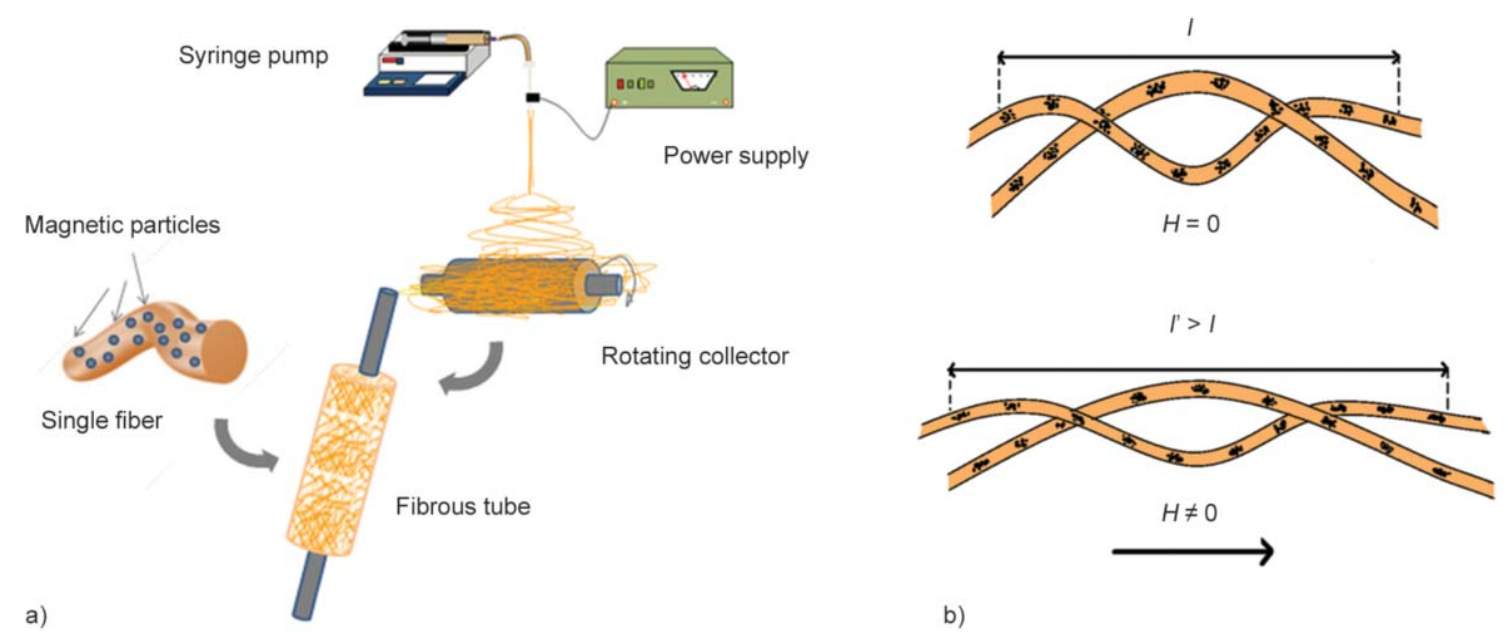

b)

Figure 1. Fabrication of elastomagnetic fibers: a) scheme of preparation of polyurethane electrospun tubes; b) schematic view of different elongation $\left(l^{\prime}>l\right)$ of fibers incorporating clusters of magnetic particle in absence $(H=0)$ and in presence $(H \neq 0)$ of an external magnetizing field

the fiber final morphology (see discussion in section 3.1). After a preliminary screening of process conditions, optimal devices were fabricated by setting a $10 \mathrm{~cm}$ gap, a voltage of $18 \mathrm{kV}$ and a flow rate of $1 \mathrm{~mL} / \mathrm{h}$, by collecting fibers for about 30 minutes. Moreover, two thin layers of polymer fibers - i.e., without magnetic particles - were collected for 6 minutes, under equal processing conditions, before and after the deposition of the MFN layer, in order to form a sandwich structure able to better confine magnetic filling particles. Thus, magnetic filler is protected by oxidation phenomena ascribable to the direct contact with external environment and, at the same time, any undesired particle extraction under the effect of a magnetic field gradient is prevented.

\subsection{Morphological analysis}

Qualitative evaluation of the elastomagnetic fibers morphology was performed by field emission scanning electron microscopy (FESEM, QUANTA200, FEI, The Netherlands). Samples were dried in the fume hood for $24 \mathrm{~h}$ in order to remove any residual solvent, mounted on metal stubs and sputter-coated with gold-palladium for about $20 \mathrm{~s}$ in order to get a $19 \mathrm{~nm}$ thick conductive layer. SEM images were taken under high vacuum conditions $\left(10^{-7}\right.$ torr $)$ at $10 \mathrm{kV}$, using the secondary electron detector (SED). On selected SEM images, the fiber diameter distribution, the mean total porous area and the $\%$ porosity were determined by using image analysis freeware (NIH ImageJ 1.37). Transmission Electron Microscopy was mainly performed to evaluate the spatial distribution of metal nanoparticles along the fibers. Bright Field
TEM analysis was performed by a FEI TECNAI G12 Spirit-Twin microscope (LaB6 source), working at $120 \mathrm{kV}$ acceleration voltage and equipped with a FEI Eagle 4k CCD camera (Eindhoven, The Netherlands). Samples were obtained by collecting fibers via electrospinning just for 60 seconds onto a carbon coated copper grid, in order to obtain few layers of fibers to be easily cross by transmitted light.

\subsection{Magneto-elastic response and characterization}

The as-produced MFN tubes (MFNTs) were preventively tested by standard tensile tests under small relative deformations - i.e., into a range from $10^{-4}$ to $10^{-3}$. An average Young Modulus equal to $0.9 \mathrm{MPa}$ and corresponding Poisson ratio of 0.48 has been obtained.

Preliminary Vibrating Sample Magnetometry analysis was also performed to take evidence of basic magnetic properties of PCU nanofibers filled with $\mathrm{Ni}$ nanoparticles. When compared to the pure Ni nanoparticle powders, the nanofibers tubular sample, produced by a solution containing $30 \%$ of $\mathrm{Ni}$ filling particles, presents an $83 \%$ decrement of saturation magnetization (from $0.77 \cdot 10^{6}$ down to $0.13 \cdot 10^{6} \mathrm{~A} / \mathrm{m}$ ). Increments of saturation and coercive fields (from $0.22 \cdot 10^{6}$ up to $0.43 \cdot 10^{6} \mathrm{~A} / \mathrm{m}$, and from $0.09 \cdot 10^{6}$ up to $0.15 \cdot 10^{6} \mathrm{~A} / \mathrm{m}$, respectively), as well as remnant magnetization ( $35 \%$ about), were observed. The reduction of saturation magnetization is higher than the expected $70 \%$. This is clearly due to presence of free volume among the deposited nanofibers (that should be the difference $83-70=13 \%$ ). On the other 
side, the increment of coercive field and remanence are justified by the deformation of the fiber which accompanies the magnetization process.

In the demagnetized status the Ni particles incorporated in the nanofibers are randomly oriented, but, if a magnetizing field $H$ is applied along the axis of a nanofibers structure, the particles magnetic moment is induced to rotate towards the magnetizing field axis, as well as the particles if they have a shape anisotropy [49]. At the same time, also the polar attraction among the magnetized particles tries to align them parallel to the magnetizing field axis. These effects into a solid matrix are totally inhibited by the mechanical reaction, but in the case of polymeric fibers that are easily deformable, a local rotation with a fiber aligning towards the tube axis is expected until the elastic reaction torque equilibrates the magnetic one [45]. Generally, any particle has a slight rotation, thus producing an elongation of the sample, namely a direct elastomagnetic effect [50]. In the case under investigation, the $\mathrm{Ni}$ particles form clusters into the fiber (average cluster width smaller than fiber diameter but length of about 5-6 particle diameter; see section 3.1 and Figure 5d. This means that the particle cluster acts as a single magnetic domain with anisotropic shape and preferential magnetization axis parallel to the fiber axis. Moreover, the fiber aligning towards an external longitudinal magnetizing field is also favored by the presence of free volume among the fibers. A qualitative exemplification of a longitudinal magnetization effect in fibers charged by magnetic clusters is shown in Figure 1b: fibers have a random curvature in the absence of a magnetizing field, but, when a magnetic field $H$ is applied, they soften their curvature, following the rotation of the clusters to align themselves with $H$ axis; as result the fibers assume a longer relative length $\left(l^{\prime}>l\right)$. For all the above reasons, the elongation due to longitudinal magnetization should be enhanced by the peculiar morphology of the produced MFN tubes, proposing them as good candidate as strain actuators [51, 52].

To demonstrate and evaluate the longitudinal strain produced by an external magnetic field on tube shaped samples the experimental apparatus shown in Figure 2a was built up. The MFNT with inner diameter of $3.0 \mathrm{~mm}$, thickness of 0.5 and $30.0 \mathrm{~mm}$ in length, is placed in vertical, locked by means of silicone glue from the bottom side and connected on the opposite side, by means of a silk thread (W), to a magnetic resonator sensor (MR); MR measures the variations of transduced stress through the wire by means of the variations in amplitude $(A)$ of resonant magnetoelastic waves in a sensor core constituted by an amorphous ferromagnetic ribbon; this waves amplitude is detected by a signal analyzer through a pick up coil (PC); the other coil, $\mathrm{C}$, is coaxial to the
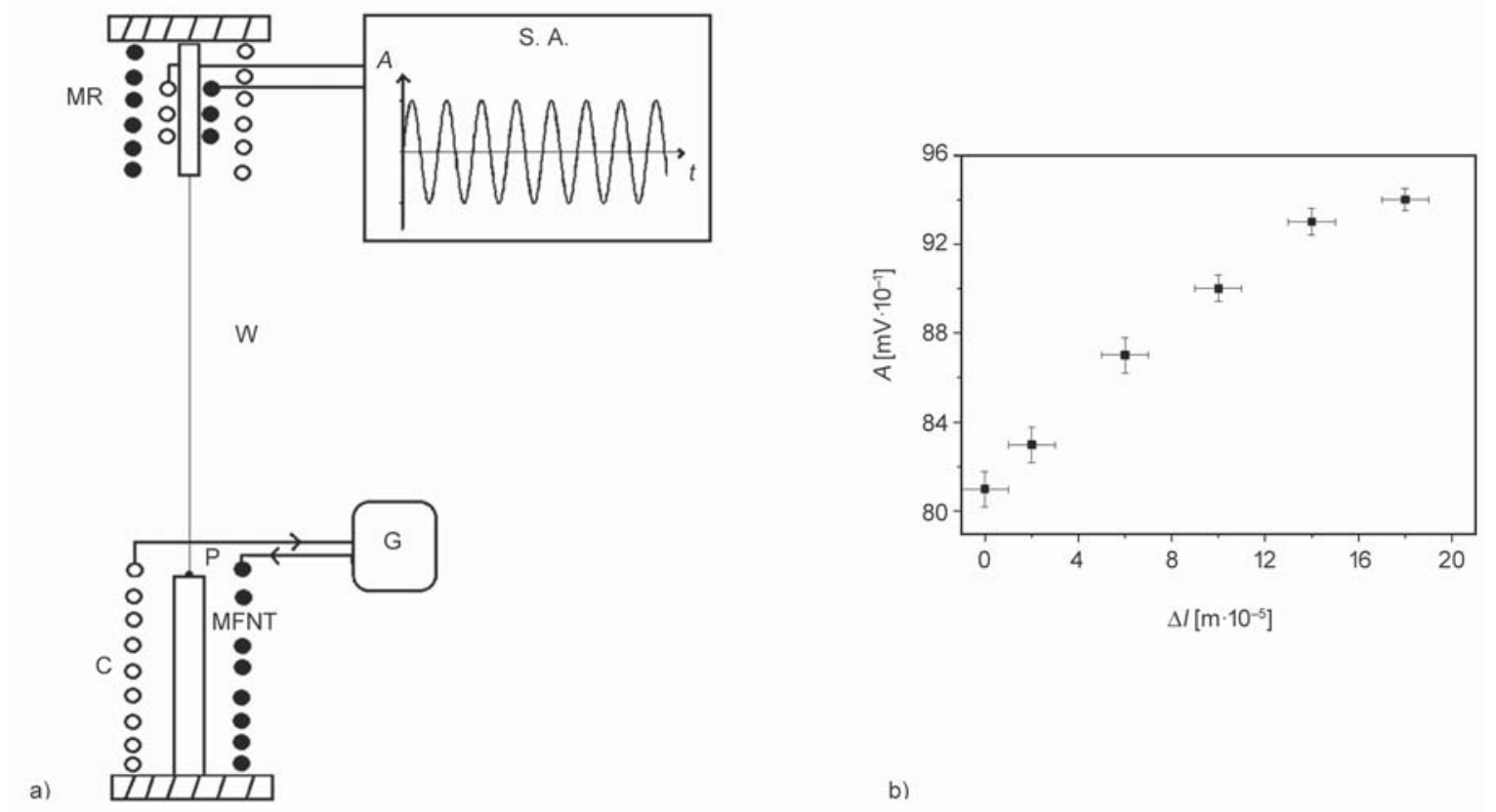

Figure 2. a) Scheme of the experimental set up used to detect a longitudinal strain induced in a MFNT by a magnetizing field; the apparatus components are described in the course of the manuscript. b) Calibration curve of the magnetoelastic resonator. $A$ is the detected amplitude of magnetoelastic resonant waves; $\Delta l$ is the $P$ point shift upward. The experimental points with errors are obtained by set of reiterated measurements. 


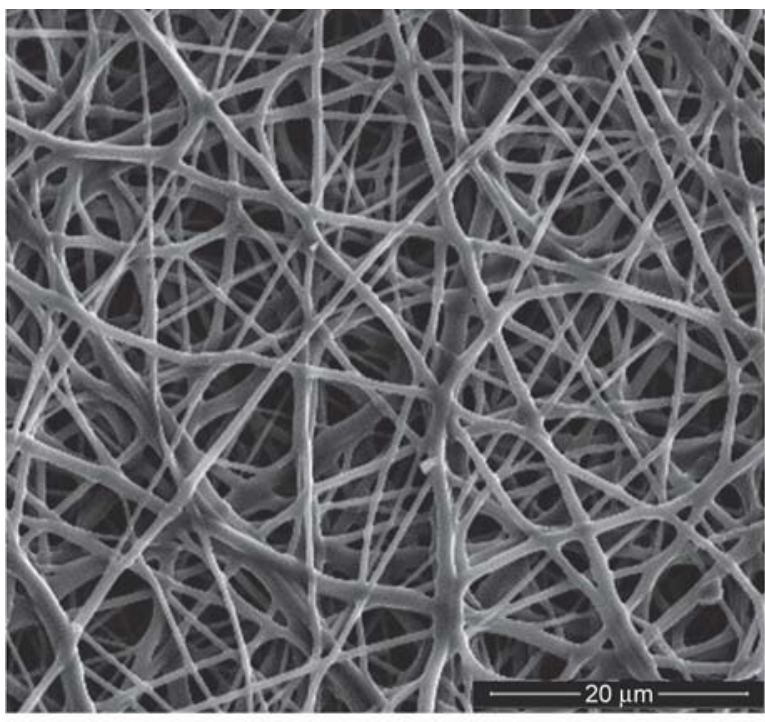

a)

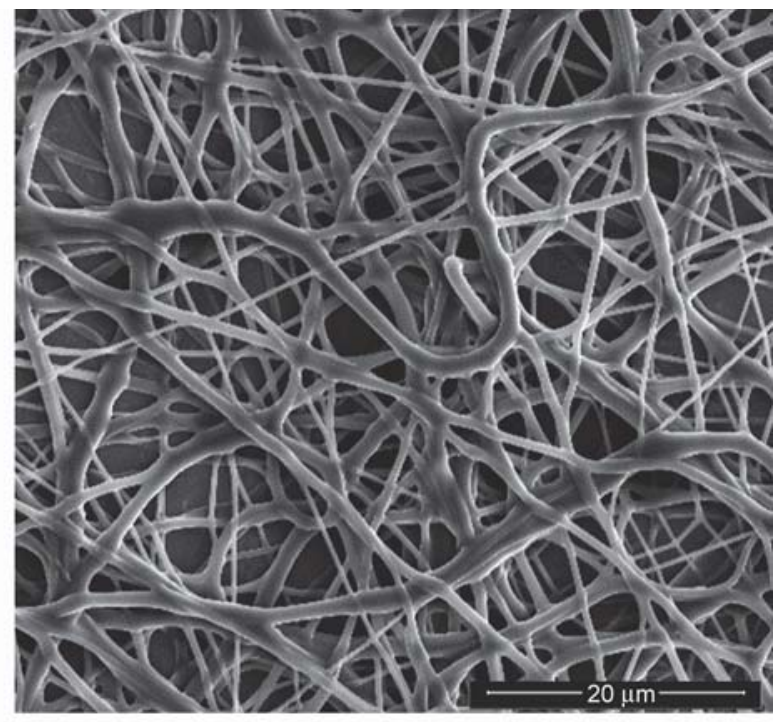

b)

Figure 3. Morphological optimization of PCU fibers: Effect of low a) and high b) flow rate on the formation of fiber defects

sample and is power supplied by a current generator $\mathrm{G}$. This generator can produce in coil $\mathrm{C}$ a constant or pulsed current at a frequency $v$ so that, by direct elastomagnetic effect a static strain, or pulsed one at the frequency $v$ is expected The working principle and detection methodology of a MR was accurately described in previous papers [53-55].

Any longitudinal strain of the sample gives a displacement of its contact point $(P)$ with the wire (W) (Figure 2a). In order to evaluate the $P$ displacement (namely, strain component) by means of the direct measure of the magnetoelastic wave amplitude, $A$, the calibration curve shown in Figure $2 b$ was preventively performed. Since the wire is pre-elongated in the starting conditions, this configuration was accurately reproduced. Then the $A$ value was monitored by producing in the $P$ point a vertical displacement upwards, with a precision of \pm 10 microns, using a precision micrometric screw.

\section{Results and discussion}

\subsection{Nanofibers and tube morphology}

PCU electrospun fibers have been investigated by SEM in order to identify the best process parameters to improve fiber spatial distribution, also minimizing the presence of defects (i.e., beads) (Figures 3 and 4). Figure 3 briefly shows a comparison of fibrous systems obtained by applying different flow rates during the electrospinning process. It has been verified that the use of higher flow rates conditions $(2 \mathrm{~mL} / \mathrm{h})$ tends to increase the presence of defects along fibers so promoting the formation of a wider distribution of fiber diameters. Contrariwise, lower flow rates
$(1 \mathrm{~mL} / \mathrm{h})$ promote the formation of more uniformly distributed fibers without beads and defects.

Figure 4 shows SEM images of PCU fibers obtained for three different voltage-to-gap $(V G)$ ratios - not only voltage - taking in consideration the contribution of critical needle/collector distance to promote the effective interaction of electrostatic forces with polymer chains, mainly in the case of viscous solutions. When the $V G$ ratio increases from $1.25 \mathrm{kV} / \mathrm{cm}$ to $1.5 \mathrm{kV} / \mathrm{cm}$, fiber diameter slightly decreases as confirmed by the left shift of average fiber diameter distribution. This is mainly ascribable to the conventional effect of increasing voltage - from 11 to $15 \mathrm{kV}$ - able to promote a higher stretching of polymer chains by forcing solvents to a more fast evaporation in agreement with previous studies on polymer nanofibers and tubes [56-59]. However, this effect is also due to the reduction of needle/collector distance from 10 to $8 \mathrm{~cm}$ - strictly required to reach the voltage threshold to break the polymer jet into fibers. A further increase of VG - up to $1.8 \mathrm{kV} / \mathrm{cm}$ - do not even reduce fiber size, but promoting a broader distribution of average fiber diameters, as a consequence of a predominant effect of instability phenomena occurring during the deposition process.

Therefore, the best conditions to fabricate nanofibers have been identified as: flow rate $(1 \mathrm{~mL} / \mathrm{h})$, Voltage $(18 \mathrm{kV})$; needle/collector gap $(10 \mathrm{~cm})$.

Fixed these parameters values, MFN elasto-magnetic tubes have been designed starting from PCU/MNPs mixture by modifying the electrospinning configuration through the introduction of rotating mandrel as collector. Figure 5 summarizes the morphological 


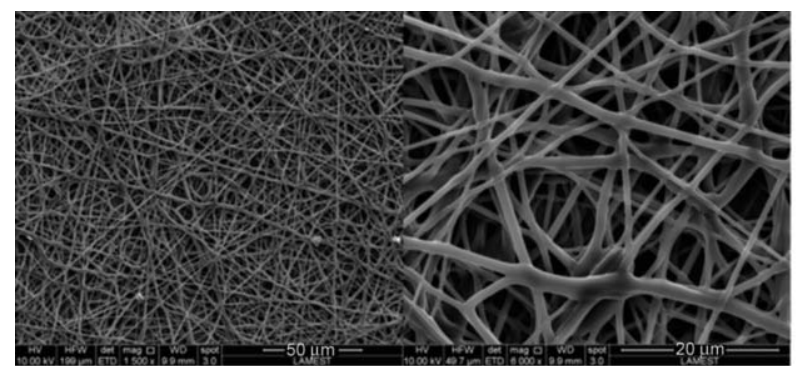

a)

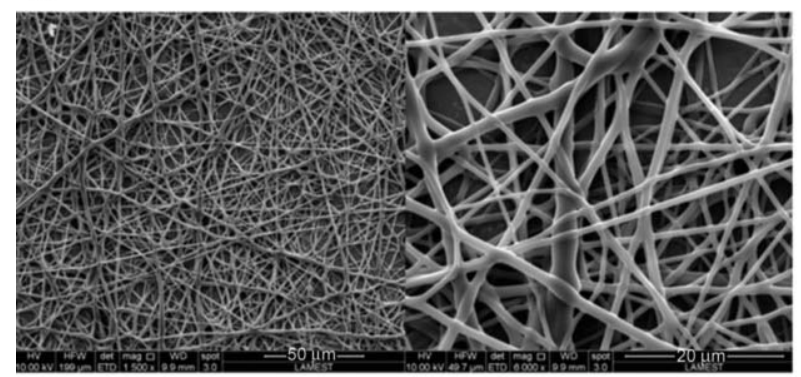

b)

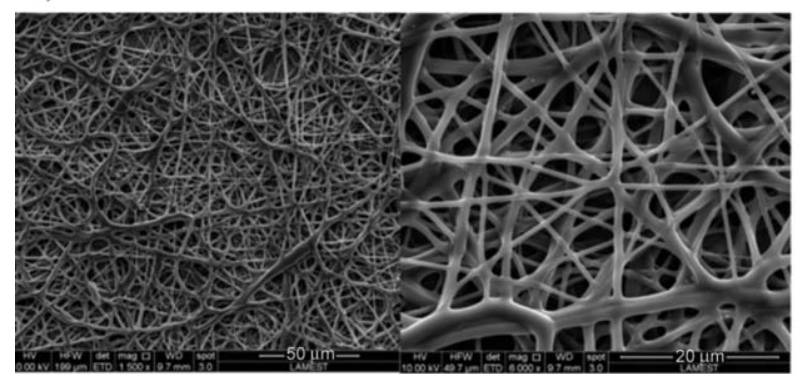

c)
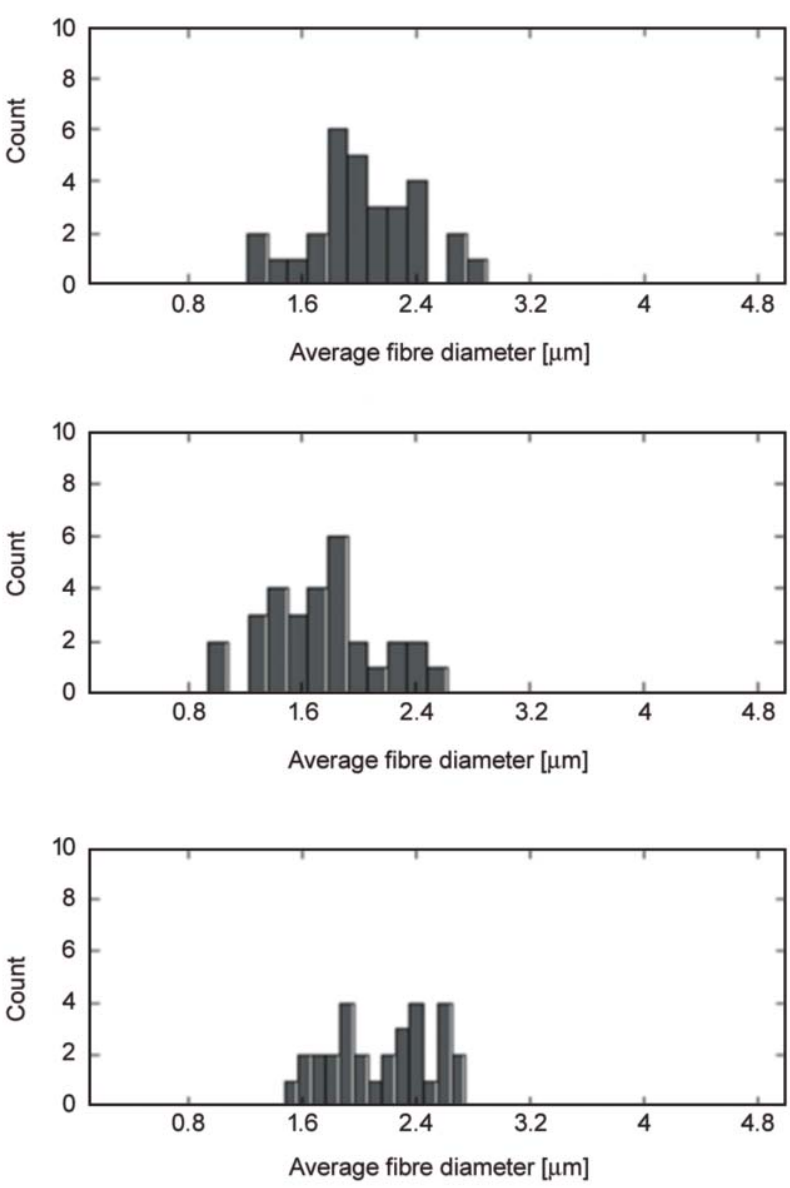

Figure 4. Morphological optimization of PCU fibers: Effect of Voltage/Gap ratio on average fiber diameter. a) $1.25 \mathrm{kV} / \mathrm{cm}$; b) $1.5 \mathrm{kV} / \mathrm{cm}$; c) $1.8 \mathrm{kV} / \mathrm{cm}$

information collected on the prototypes. The presence of magnetic MNPs is clearly remarked just at the macroscale, by comparing different sample staining (grey instead of white - Figure 5a). Cross section images reported in Figure $5 \mathrm{~b}$ allows investigating tubular shape aspect of samples characterized by a homogeneous distribution of wall thickness with average value of $450 \pm 73 \mu \mathrm{m}$.

By exploring the surface at the micrometric size scale (Figure 5c), it is possible to recognize a random fiber mat with average fiber diameter of $1.82 \pm 0.43 \mu \mathrm{m}$. In comparison with unloaded fibers with average diameter of $1.68 \pm 0.51 \mu \mathrm{m}$, MNPs do not significantly influence the morphology of fibers. This may be also explained by their peculiar spatial distribution into the fibers (Figure 5d) and their average size, ca. one order of magnitude lower than that of fiber diameters (Figure 5e). However, MNPs tend to form small aggregates (Figure 5d) composed of ca. 10 units, not homogeneously distributed along the fiber body. As a consequence, they work as sub-micrometric particle clusters which do not show direct contacts but are embedded into the polymer matrix, so exerting, effectively, the expected elastomagnetic properties, predicted in section 2.3 and confirmed by the experimental data reported in the following section.

\subsection{Direct elastomagnetic effect}

Despite the non-homogeneous distribution of MNPs, it is significant that when MFNT, peeled off from the mandrel substrate, is under the action of a transversal magnetic field gradient, it exhibits a considerable stretching of the fibers, accompanied by reversible flexural (longitudinal and transversal) strains.

The effect is qualitatively described in Figure 6 where a fibrous tube is evidently bent under the action of permanent magnets. The bending mechanism is similar to that described in the discussion related to Figure $1 \mathrm{~b}$. In effect, the formation of particles clusters with an enhanced magnetic moment determines their aligning along the magnetic field lines: the particle clusters displace and rotate producing the fibers (and tube) deflection. In particular, the free extreme displacement in Figure 6 is around $2 \mathrm{~cm}$. 


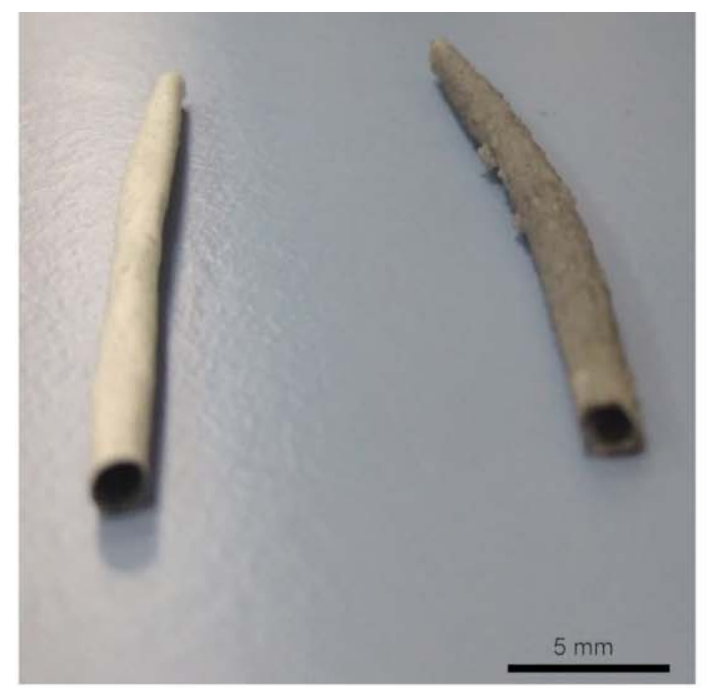

a)

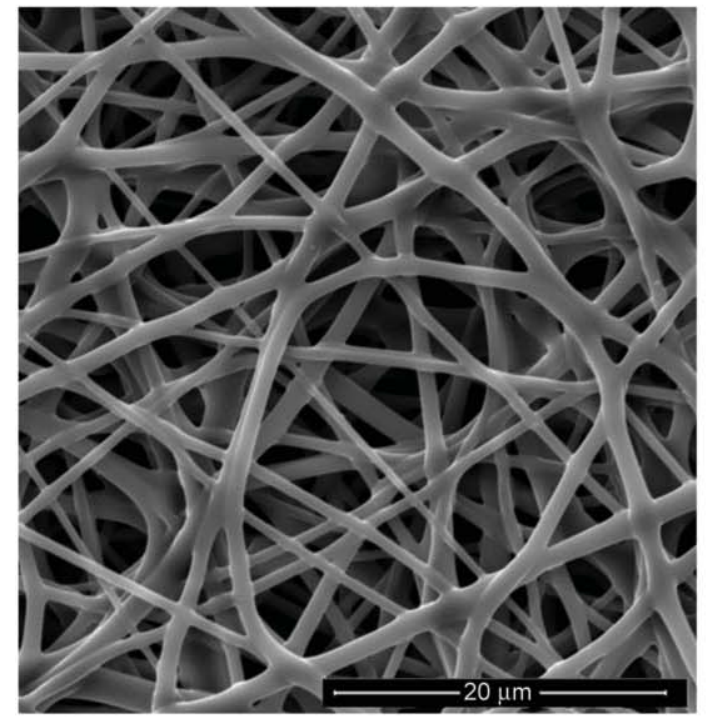

c)

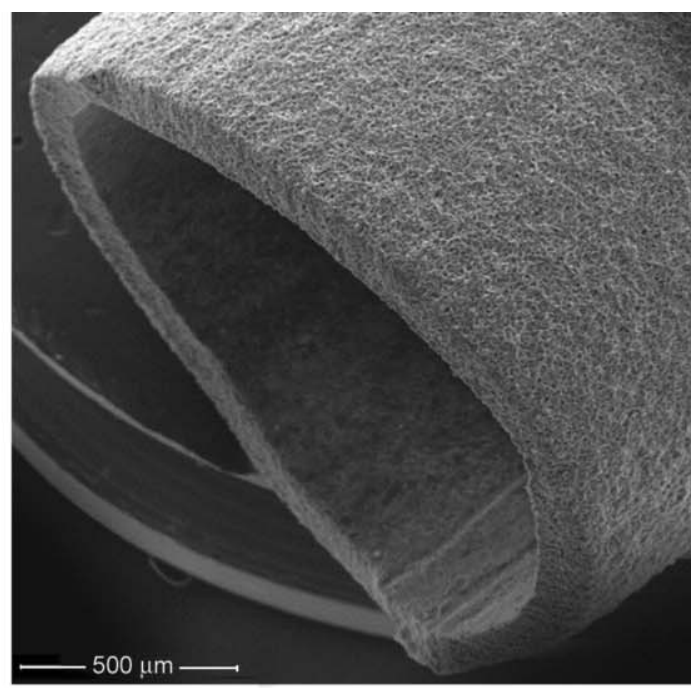

b)

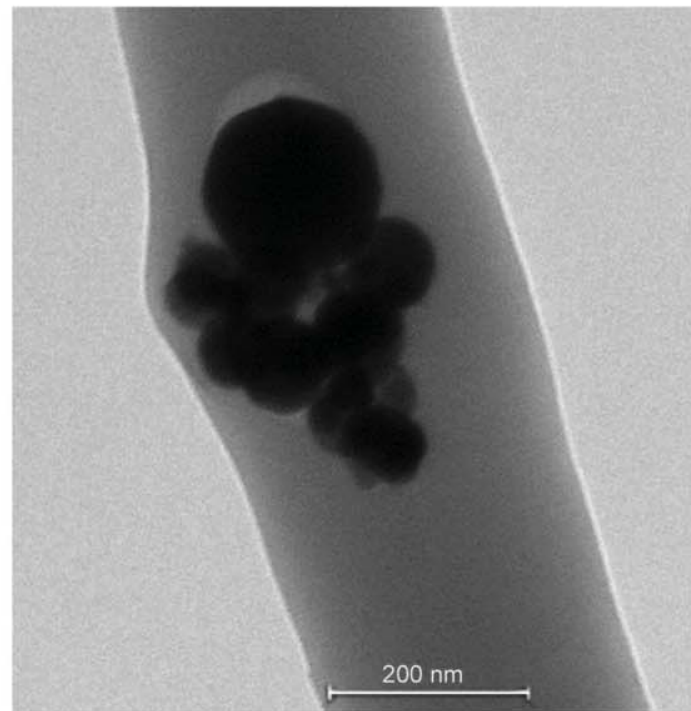

d)

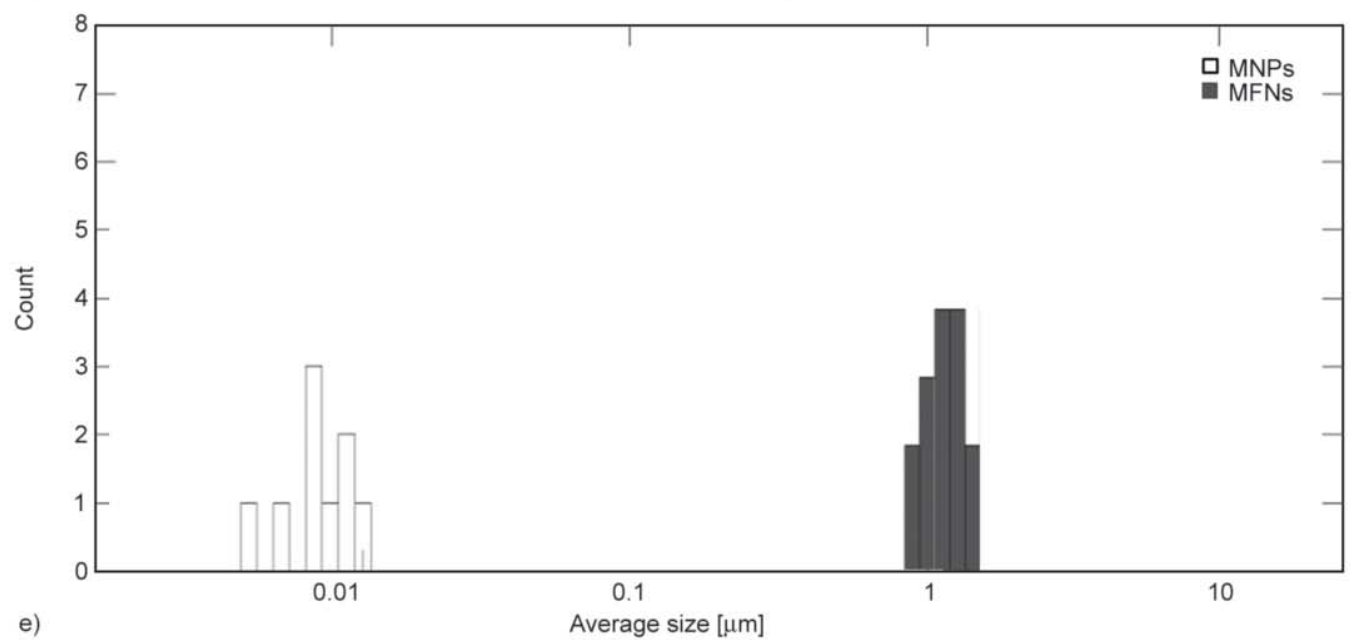

Figure 5. Elastomagnetic tubes: qualitative evidence of different staining of particle loaded and unloaded tubes a); SEM images of tube cross-section b) and surface c); TEM image of nanoparticle clusters along the fibers d); and particle/MFN size distribution e)

Figure 6 wants to give a qualitative visualization of the induced deformation, but is not appropriate to quantify the longitudinal elongation of the tubular sample. To this purpose, the experimental apparatus described in section 2.3 has been dedicated. In Figure 7, the behavior of A (amplitude of the resonant 

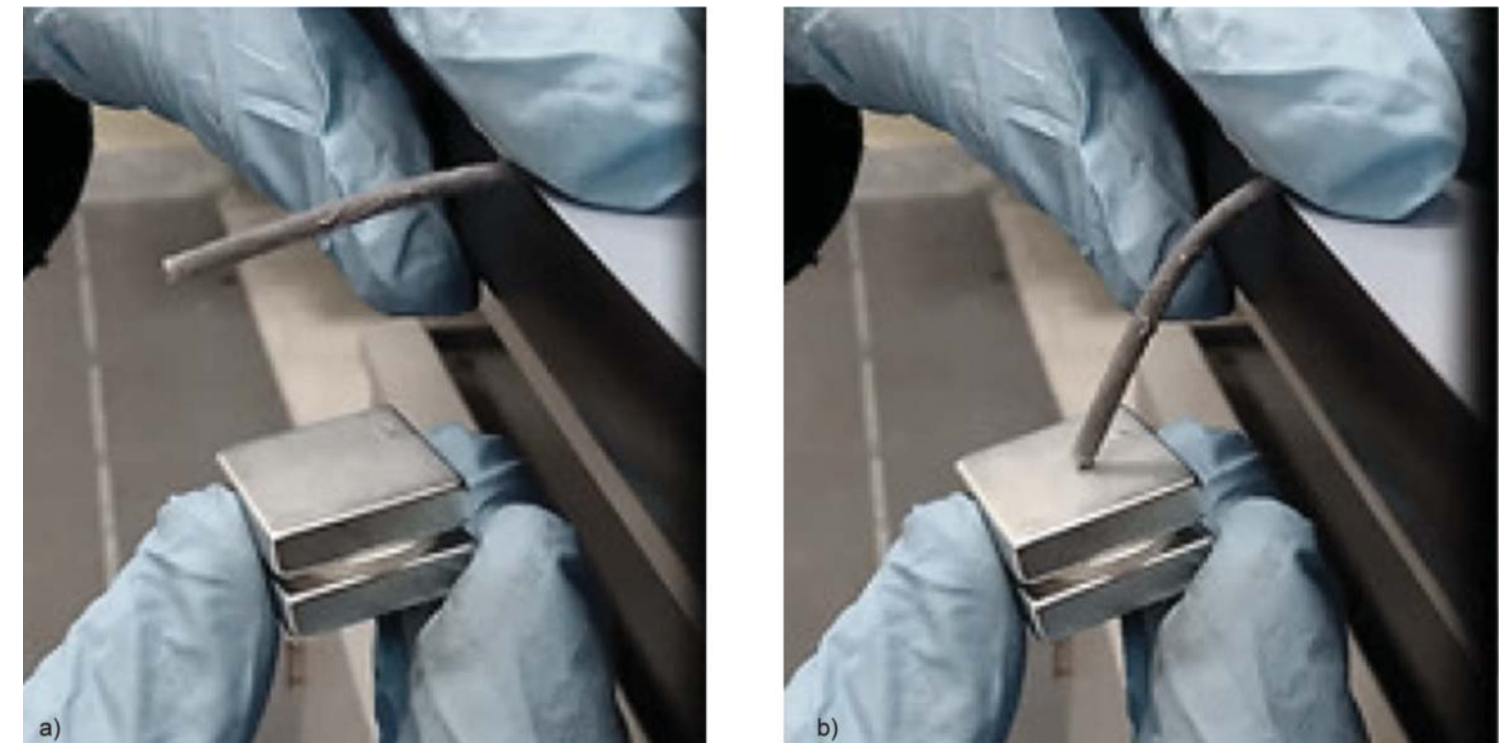

Figure 6. Strain response of MFNTs in presence of a magnetic field gradient generated by a permanent magnet. When the gradient of the external magnetizing field is increased by decreasing the magnet distance, the MFNT is clearly deflected and strained as consequence of the direct elastomagnetic effect. a) slight deflection due to the magnet, shown in the figure, placed at a distance of $32 \mathrm{~mm}$ from the tube axis; b) large deflection obtained by decreasing the distance to $28 \mathrm{~mm}$

magnetoelastic waves detected by the sensor in Figure 2a) was reported as a function of different external condition on the MFNTs: $\left(^{*}\right)$ sample not connected to wire (sensor core free of any tensile stress); (0) sample connected to wire $(H=0)$; (1) sample connected to wire with static external magnetic field $H=1.5 \cdot 10^{4} \mathrm{~A} / \mathrm{m}$; (2) sample connected to wire with pulsed external magnetic field (amplitude $\Delta H=$ $1.5 \cdot 10^{4} \mathrm{~A} / \mathrm{m}$; interval between two subsequent pulses $\Delta T=1 / v ; v=10 \mathrm{~Hz}$ ); (3) same conditions of case (2) but $v=100 \mathrm{~Hz}$; (4) same conditions of case (2) but $v=1000 \mathrm{~Hz}$; (5) same pulsed field as in case (3) but without any elastomagnetic tube into the coil.

By means of the calibration curve in Figure $2 b$ it is also possible to deduce from the $A$ values the corresponding $\Delta l$ values (vertical scale on the right in Figure 7), namely the displacement of extreme $P$ of the tube, under the different magnetization condition.

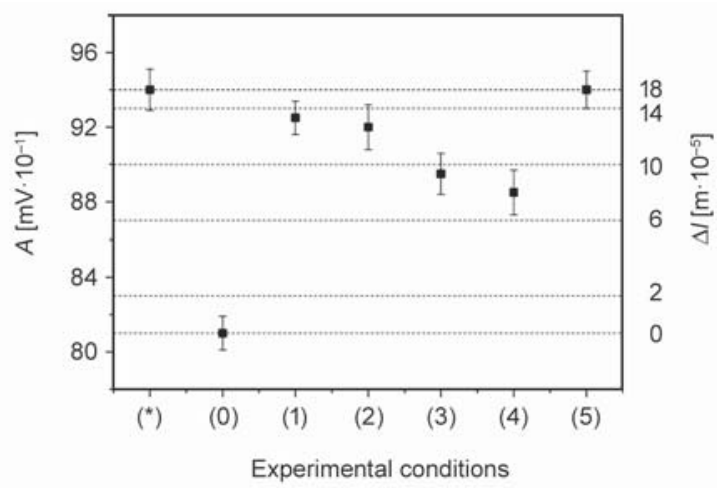

Figure 7. Behaviour of magnetoelastic waves amplitude detected by MR versus the adopted experimental condition as listed in Table 1.

Table 1. Experimental condition data and corresponding elastomagnetic results

\begin{tabular}{|c|l|c|c|c|c|c|}
\hline Symbol & \multicolumn{1}{|c|}{$\mathbf{S S}$} & $\begin{array}{c}\boldsymbol{H} \\
{\left[\mathbf{1 0}^{\mathbf{4}} \mathbf{A} / \mathbf{m}\right]}\end{array}$ & $\begin{array}{c}\Delta \boldsymbol{H} \\
{\left[\mathbf{1 0}^{\mathbf{4}} \mathbf{A} / \mathbf{m}\right]}\end{array}$ & $\begin{array}{c}\mathbf{v} \\
{[\mathbf{H z}]}\end{array}$ & $\begin{array}{c}\Delta \boldsymbol{L} \\
{\left[\mathbf{1 0}^{-\mathbf{5}} \mathbf{m}\right]}\end{array}$ & $\begin{array}{c}\boldsymbol{\varepsilon} \\
{\left[\mathbf{1 0}^{-\mathbf{3}}\right]}\end{array}$ \\
\hline$\left(^{*}\right)$ & Present but disconnected & 0 & 0 & 0 & $/ /$ & 0 \\
\hline$(0)$ & connected & 0 & 0 & 0 & 0 & 0 \\
\hline$(1)$ & connected & 1.5 & 0 & 0 & 13 & 4.3 \\
\hline$(2)$ & connected & 0 & 1.5 & 10 & 12 & 4.0 \\
\hline$(3)$ & connected & 0 & 1.5 & 100 & 10 & 3.3 \\
\hline$(4)$ & connected & 0 & 1.5 & 1000 & 8 & 2.7 \\
\hline$(5)$ & absent & 1.5 & 100 & $1 /$ & $/ /$ \\
\hline
\end{tabular}

Legend: SS = Sample Status; $H=$ static applied magnetizing field; $\Delta H=$ pulsed applied magnetizing field amplitude; $v=$ pulsed field frequency; $\Delta L=$ sample elastomagnetic elongation; $\varepsilon=$ elastomagnetic strain 
The following deductions can be obtained: (i) the application of a static $H$ field induces the MFNT elongation because the $A$ amplitude increases due to tension decrease into the silk wire (step from (0) to (1) $-P$ shift upward); (ii) the application of a pulsed magnetic field gives a periodic elongation of the MFNT that at low frequency is comparable with static deformation, but decreases slightly with increasing frequency (decrease of $A$ going from (2) towards (4)); (iii) the A variation is not due to direct induction effect of the magnetic field on the MR (compare $(*)$ and (5) - the sensor is well shielded from external magnetic field); (iv) the initial pre-tensile displacement is about $180 \mu \mathrm{m}$.

Definitely, the expected direct elastomagnetic effect is verified. By comparison with the calibration curve a static sample elongation of about $130 \pm 10 \mu \mathrm{m}$ is deduced as effect of $H$ magnetization, which considering the tube length means a longitudinal strain component $\varepsilon \sim 4 \cdot 10^{-3}$.

This result deserves interest not only from the scientific point of view because it demonstrates (and measures) the presence of direct elastomagnetic longitudinal deformation, but also for the relevance in applications when it is required not only a simple deflection but an effective longitudinal (and related transversal) strain of tubular device. In effect, together longitudinal strain of $4 \cdot 10^{-3}$, standing the measured Poisson ratio, it has also a transversal strain (relative change of radius) of about $2 \cdot 10^{-3}$. Such a transversal strain, accompanying tube longitudinal oscillation, can be very useful in biomedical field, for example, when the contents of the tube need to be pressurized in order of a better drain. On the contrary, we still have to work on electrical and energy transduction capabilities, to be able to contemplate applications in the field of artificial intelligence or robotics $[60,61]$ for MFNTs here investigated.

\section{Conclusions}

It has been developed the electrospinning fabrication of PCU fibers incorporating clusters of magnetic nanoparticles up to ca. $30 \%$ in volume fraction, however preventing the direct contact among magnetic clusters. Then, these MFNs have been assembled in tube shaped samples by the use of tailored electrospinning set up. It has been shown that MFNTs exhibit a macroscopic deflection when submitted to a transversal magnetic field. Quantitative experimental results have demonstrated that both static and dynamic elongation may be induced by means of static or dynamic longitudinal magnetization. A noticeable elastomagnetic strain component - about $4 \cdot 10^{-3}$ has been recorded, taking into account the moderate value of the used exciting magnetizing field ( $H=$ $1.4 \cdot 10^{4} \mathrm{~A} / \mathrm{m}$ ). The produced MNFTs have both inside and outside a layer of polymeric fibers that prevents the contact of the particles incorporated in the core with the external environment. All these features prospect the possibility to use innovative MFN agglomerations for the fabrication of stents, cardiac patches or artificial nerve guides, able to be deformed under the application of a controlled external magnetic field. In particular, similar devices could be used for vibration therapy or to fabricate prosthesis tubes, able to have strain or/and oscillation to remove undesirable agents, i.e. kidney stones in a urethral duct or a thrombotic clots in blood vessels.

\section{Acknowledgements}

Transmission and Scanning Electron Microscopy were supported by Lamest Labs of the National Research Council of Italy. We are grateful to Dr. Luca Lanotte (Researcher at INRA Institute, Rennes France).

\section{References}

[1] Gu J., Lv Z., Wu Y., Guo Y., Tiam L., Qiu H., Li W., Zhang Q.: Dielectric thermally conductive boron nitride/polyimide composites with outstanding thermal stabilities via in-situ polymerization-electrospinninghot press method. Composites Part A: Applied Science and Manufacturing, 94, 209-216 (2017). https://doi.org/10.1016/j.compositesa.2016.12.014

[2] Zhao W., Li J., Jin K., Liu W., Qiu X., Li C.: Fabrication of functional PLGA-based electrospun scaffolds and their applications in biomedical engineering. Materials Science and Engineering C, 59, 1181-1194 (2016). https://doi.org/10.1016/j.msec.2015.11.026

[3] Tian L., Gu J., Lei X., Lv Z., Qiao M., Yin C., Zhang Q.: Fabrication and characterization of electrospun dopants/PS composite fibers with porous and hollowporous structures. Macromolecular Materials and Engineering, 301, 625-635 (2016). https://doi.org/10.1002/mame.201600013

[4] Gu J., Lv J., Wu Y., Zhao R., Tian L., Zhang Q.: Enhanced thermal conductivity of $\mathrm{SiCp} / \mathrm{PS}$ composites by electrospinning-hot press technique. Composites Part A: Applied Science and Manufacturing, 79, 8-13 (2015). https://doi.org/10.1016/j.compositesa.2015.09.005 
[5] Almajhdi F. N., Fouad H., Khalil K. A., Awad A. M., Mohammed S. H., Elsanagawy T., Albarrag A. M., AlJassir F. F., Abdo H. S.: In-vitro anticancer and antimicrobial activities of PLGA/silver nanofiber composites prepared by electrospinning. Journal of Materials Science: Materials in Medicine, 25, 1045-1053 (2014). https://doi.org/10.1007/s10856-013-5131-y

[6] Starost K., Frijns E., van Laer J., Faisal N., Egizzabal A., Elizextea C., Blazquez M., Nelissen I., Njuguna J.: Assessment of nanoparticles release into the environment during drilling of carbon nanotubes/epoxy and carbon nanofibres/epoxy nanocomposites. Journal of Hazardous Materials, 340, 57-66 (2017). https://doi.org/10.1016/j.jhazmat.2017.06.057

[7] Guo Z., Park S., Hahn H. T., Wei S., Moldovan M., Karki A. B., Young D. P.: Magnetic and electromagnetic evaluation of the magnetic nanoparticle filled polyurethane nanocomposites. Journal of Applied Physics, 101, 09M511/1-09M511/3 (2007).

https://doi.org/10.1063/1.2711074

[8] Kim D. K., Zhang Y., Voit W., Rao K. V., Muhammed M.: Synthesis and characterization of surfactant-coated superparamagnetic monodispersed iron oxide nanoparticles. Journal of Magnetism and Magnetic Materials, 225, 30-36 (2001). https://doi.org/10.1016/S0304-8853(00)01224-5

[9] Guo Z., Lee S-E., Kim H., Park S., Hahn H. T., Karki A. B., Young D. P.: Fabrication, characterization and microwave properties of polyurethane nanocomposites reinforced with iron oxide and barium titanate nanoparticles. Acta Materialia, 57, 267-277 (2009).

https://doi.org/10.1016/j.actamat.2008.09.024

[10] Guo Z., Park S., Wei S., Pereira T., Moldovan M., Karki A. B., Young D. P., Hahn H. T.: Flexible high-loading particle-reinforced polyurethane magnetic nanocomposite fabrication through particle-surface-initiated polymerization. Nanotechnology, 18, 335704/1-335704/8 (2007). https://doi.org/10.1088/0957-4484/18/33/335704

[11] Zhu J., Wei S., Chen X., Karki A. B., Rutman D., Young D. P., Guo Z.: Electrospun polyimide nanocomposite fibers reinforced with core-shell $\mathrm{Fe}-\mathrm{FeO}$ nanoparticles. Journal of Physical Chemistry, 114, 8844-8850 (2010). https://doi.org/10.1021/jp1020033

[12] Wei Y., Zang X., Song Y., Han B., Hu X., Wang X., Lin Y., Deng X.: Magnetic biodegradable $\mathrm{Fe}_{3} \mathrm{O}_{4} / \mathrm{CS} / \mathrm{PVA}$ nanofibrous membranes for bone regeneration. Biomedical Materials, 6, 055008/1-055008/15 (2011). https://doi.org/10.1088/1748-6041/6/5/055008

[13] Meng J., Xiao B., Zhang Y., Liu J., Xue H., Lei J., Kong H., Huang Y., Jin Z., Gu N., Xu H.: Super-paramagnetic responsive nanofibrous scaffolds under static magnetic field enhance osteogenesis for bone repair in vivo. Scientific Report, 3, 2655/1-2655/7 (2013).

https://doi.org/10.1038/srep02655
[14] Zeng X. B., Hu H., Xie L. Q., Lan F., Jiang W., Wu Y., $\mathrm{Gu}$ Z. W.: Magnetic responsive hydroxyapatite composite scaffolds construction for bone defect reparation. International Journal of Nanomedicine, 7, 3365-3378 (2012).

https://doi.org/10.2147/IJN.S32264

[15] Shan D., Shi Y., Duan S., Wei Y., Cai Q., Yang X.: Electrospun magnetic poly(L-lactide) (PLLA) nanofibers by incorporating PLLA-stabilized $\mathrm{Fe}_{3} \mathrm{O}_{4}$ nanoparticles. Materials Science and Engineering: C, 33, 3498-3505 (2013). https://doi.org/10.1016/j.msec.2013.04.040

[16] Li L., Yang G., Li J, Ding S., Zhou S.: Cell behaviors on magnetic electrospun poly-D, L-lactide nanofibers. Materials Science and Engineering: C, 34 252-261 (2014). https://doi.org/10.1016/j.msec.2013.09.021

[17] Lin T-C., Lin F-H., Lin J-C.: In vitro characterization of magnetic electrospun IDA-grafted chitosan nanofiber composite for hyperthermic tumor cell treatment. Journal of Biomaterials Science, Polymer Edition, 24, 1152-1163 (2013).

https://doi.org/10.1080/09205063.2012.743061

[18] Liu M., Liu H., Sun S., Li X., Zhou Y., Hou Z., Lin J.: Multifunctional hydroxyapatite/Na(Y/Gd)F4: $\mathrm{Yb}^{3+}, \mathrm{Er}^{3+}$ composite fibers for drug delivery and dual modal imaging. Langmuir, 30, 1176-1182 (2014).

https://doi.org/10.1021/la500131d

[19] Ganesh N., Ashokan A., Rajeshkannan R., Chennazhi K., Koyakutty M., Nair S. V.: Magnetic resonance functional nano-hydroxyapatite incorporated poly(caprolactone) composite scaffolds for in situ monitoring of bone tissue regeneration by MRI. Tissue Engineering Part A, 20, 2783-2794 (2014).

https://doi.org/10.1089/ten.tea.2014.0161

[20] Preslar A. T., Parigi G., McClendon M. T., Sefick S. S., Moyer T. J., Haney C. R., Waters E. A., MacRenaris K. W., Luchinat C., Stupp S. I., Meade T. J.: Gd(III)-labeled peptide nanofibers for reporting on biomaterial localization in vivo. ACS Nano, 8, 7325-7332 (2014). https://doi.org/10.1021/nn502393u

[21] Wang B., Zheng H., Chang M-W., Ahmad Z., Li J-S.: Hollow polycaprolactone composite fibers for controlled magnetic responsive antifungal drug release. Colloids and Surfaces B: Biointerfaces, 145, 757-767 (2016). https://doi.org/10.1016/j.colsurfb.2016.05.092

[22] Ma Q., Wang J., Dong X., Yu W., Liu G.: Electrospinning fabrication of high-performance magnetic@photoluminescent bifunctional coaxial nanocables. Chemical Engineering Journal, 222, 16-22 (2013). https://doi.org/10.1016/j.cej.2013.02.063

[23] Huang Z-M., Zhang Y-Z., Kotaki M., Ramakrishna S.: A review on polymer nanofibers by electrospinning and their applications in nanocomposites. Composites Science and Technology, 63, 2223-2253 (2003). https://doi.org/10.1016/S0266-3538(03)00178-7 
[24] Zhang D., Karki A. B., Rutman D., Young D. P., Wang A., Cocke D., Ho T. H., Guo Z.: Electrospun polyacrylonitrile nanocomposite fibers reinforced with $\mathrm{Fe}_{3} \mathrm{O}_{4}$ nanoparticles: Fabrication and property analysis. Polymer, 50, 4189-4198 (2009).

https://doi.org/10.1016/j.polymer.2009.06.062

[25] Wu H., Zhang R., Liu X., Lin D., Pan W.: Electrospinning of Fe, Co, and Ni nanofibers: Synthesis, assembly, and magnetic properties. Chemistry of Materials, 19, 3506-3511 (2007).

https://doi.org/10.1021/cm070280i

[26] Wang L., Yu Y., Chen P-C., Chen C-H.: Electrospun carbon-cobalt composite nanofiber as an anode material for lithium ion batteries. Scripta Materialia, 58, 405-408 (2008).

https://doi.org/10.1016/j.scriptamat.2007.10.024

[27] Shao C., Yu N., Liu Y., Mu R.: Preparation of LiCoO2 nanofibers by electrospinning technique. Journal of Physics and Chemistry of Solids, 67, 1423-1426 (2006). https://doi.org/10.1016/j.jpcs.2006.01.104

[28] Guan H., Shao C., Liu Y., Yu N., Yang X.: Fabrication of NiCo2O 4 nanofibers by electrospinning. Solid State Communications, 131, 107-109 (2004).

https://doi.org/10.1016/j.ssc.2004.04.035

[29] Li D., Herricks T., Xia Y.: Magnetic nanofibers of nickel ferrite prepared by electrospinning. Applied Physics Letters, 83, 4586-4588 (2003). https://doi.org/10.1063/1.1630844

[30] Jamal E. M. A., Joy P. A., Kurian P., Anantharaman M. R.: Synthesis of nickel-rubber nanocomposites and evaluation of their dielectric properties. Materials Science and Engineering: B, 156, 24-31 (2009). https://doi.org/10.1016/j.mseb.2008.10.041

[31] Chen X., Wei S., Gunesoglu C., Zhu J., Southworth C. S., Sun L., Karki A. B., Young D. P., Guo Z.: Electrospun magnetic fibrillar polystyrene nanocomposites reinforced with nickel nanoparticles. Macromolecular Chemistry and Physics, 211, 1775-1783 (2010). https://doi.org/10.1002/macp.201000153

[32] Wang L., Gai G., Xiao X. Gao S.: Fabrication of magnetic-luminescent bifunctional composite nanofibers via facile electrospinning. Journal of Materials Science: Materials in Electronics, 25, 3147-3153 (2014). https://doi.org/10.1007/s10854-014-1996-x

[33] Ahn B. W., Kang T. J.: Preparation and characterization of magnetic nanofibers with iron oxide nanoparticles and poly(ethylene terephthalate). Journal of Applied Polymer Science, 125, 1567-1575 (2012).

https://doi.org/10.1002/app.34953

[34] Mordina B., Tiwari R. K., Setua D. K., Sharma A.: Superior elastomeric nanocomposites with electrospun nanofibers and nanoparticles of $\mathrm{CoFe}_{2} \mathrm{O}_{4}$ for magnetorheological applications. RSC Advances, 5, 1909119105 (2015). https://doi.org/10.1039/C5RA00537J
[35] Burke L., Mortimer C. J., Curtis D. J., Lewis A. R., Williams R., Hawkins K., Maffeis T. G. G., Wright C. J.: In-situ synthesis of magnetic iron-oxide nanoparticle-nanofibre composites using electrospinning. Materials Science and Engineering: C, 70, 512-519 (2017). https://doi.org/10.1016/j.msec.2016.09.014

[36] Sorokin V. V., Stepanov G. V., Shamonin M., Monkman G. J., Khokhlov A. R., Kramarenko E. Y.: Hysteresis of the viscoelastic properties and the normal force in magnetically and mechanically soft magnetoactive elastomers: Effects of filler composition, strain amplitude and magnetic field. Polymer, 76, 191-202 (2015).

https://doi.org/10.1016/j.polymer.2015.08.040

[37] Jedlovszky-Hajdu A., Molnar K., Nagy P. M., Sinko K., Zrinyi M.: Preparation and properties of a magnetic field responsive three-dimensional electrospun polymer scaffold. Colloids and Surfaces A: Physicochemical and Engineering Aspects, 503, 79-87 (2016).

https://doi.org/10.1016/j.colsurfa.2016.05.036

[38] Gutiérrez J., Lasheras A., Martins P., Pereira N., Barandiarán J. M, Lanceros-Mendez S.: Metallic glass/PVDF magnetoelectric laminates for resonant sensors and actuators: A review. Sensors, 17, 1251/1-1251/18 (2017). https://doi.org/10.3390/s17061251

[39] Ausanio G., Hison C. L., Iannotti V., Lanotte L., Lanotte L.: Magneto-piezoresistance in elastomagnetic composites. Journal of Applied Physics, 110, 063903/1-063903/5 (2011).

https://doi.org/10.1063/1.3634120

[40] Iannotti V., Ausanio G., Lanotte L., Lanotte L.: Magneto-piezoresistivity in iron particle-filled silicone: An alternative outlook for reading magnetic field intensity and direction. Express Polymer Letters, 10, 65-71 (2016). https://doi.org/10.3144/expresspolymlett.2016.7

[41] Ajili S. H., Ebrahimi N. G., Soleimani M.: Polyurethane/polycaprolactane blend with shape memory effect as a proposed material for cardiovascular implants. Acta Biomaterialia, 5, 1519-1530 (2009). https://doi.org/10.1016/j.actbio.2008.12.014

[42] Schwartz C. J., Bahadur S.: Development and testing of a novel joint wear simulator and investigation of the viability of an elastomeric polyurethane for total-joint arthroplasty devices. Wear, 262, 331-339 (2007). https://doi.org/10.1016/j.wear.2006.05.018

[43] Christenson E. M., Dadsetan M., Wiggins M., Anderson J. M., Hiltner A.: Poly(carbonate urethane) and poly (ether urethane) biodegradation: In vivo studies. Journal of Biomedical Materials Research A, 9, 407-416 (2004). https://doi.org/10.1002/jbm.a.30002

[44] Wijeyaratne S. M., Kannangara L.: Safety and efficacy of electrospun polycarbonate-urethane vascular graft for early hemodialysis access: first clinical results in man. The Journal of Vascular Access, 12, 28-35 (2011). https://doi.org/10.5301/JVA.2011.6278 
[45] Lanotte L., Ausanio G., Iannotti V., Pepe G., Carotenuto G., Netti P., Nicolais L.: Magnetic and magnetoelastic effects in a composite material of Ni microparticles in a silicone matrix. Physical Review B, 63, 054438/1054438/6 (2011).

https://doi.org/10.1103/PhysRevB.63.054438

[46] Ausanio G., Iannotti V., Lanotte L., Lanotte L.: Optimizatiom of coupling between piezoresistivity and magnetoelasticity in an elastomagnetic composite to sense a spatial gradient of magnetic field. European Physical Journal B, 86, 1-5 (2013).

https://doi.org/10.1140/epjb/e2012-30657-1

[47] Jose M. V., Thomas V., Johson K. T., Dean D. R., Nyairo E.: Aligned PLGA/HA nanofibrous nanocomposite scaffolds for bone tissue engineering. Acta Biometeriala, 5, 305-315 (2009).

https://doi.org/10.1016/j.actbio.2008.07.019

[48] Zhang D., Karki A. B., Rutman D., Young D. P., Wang A., Cocke D., Ho T. H., Guo Z.: Electrospun polyacrylonitrile nanocomposite fibers reinforced with $\mathrm{Fe}_{3} \mathrm{O}_{4}$ nanoparticles: Fabrication and property analysis. Polymer, 50, 4189-4198 (2009).

https://doi.org/10.1016/j.polymer.2009.06.062

[49] Iannotti V., Ausanio G., Campana C., D’Orazio F., Hison C., Lucari F., Lanotte L.: Magnetic anisotropy in $\mathrm{Ni}-\mathrm{Si}$ nanoparticle films produced by ultrashort pulsed laser deposition. Journal of Magnetism and Magnetic Materials, 320, e594-e598 (2008).

https://doi.org/10.1016/j.jmmm.2008.04.038

[50] Lanotte L., Ausanio G., Hison C., Iannotti V., Luponio C.: The potentiality of composite elastic magnets as novel materials for sensors and actuators. Sensors and Actuators A: Physical, 106, 56-60 (2003).

https://doi.org/10.1016/S0924-4247(03)00133-X

[51] Ausanio G., Campana C., Hison C., Iannotti V., Lanotte L.: Linearity of the direct elastomagnetic effect: Evaluation and limits. Smart Materials and Structures, 16, 570-574 (2007).

https://doi.org/10.1088/0964-1726/16/3/003

[52] Ausanio G., Hison C., Iannotti V., Luponio C., Lanotte L.: Elastomagnetic effect in novel elastic magnets. Journal of Magnetism and Magnetic Materials, 272-276, 2069-2071 (2004).

https://doi.org/10.1016/j.jmmm.2003.12.1170
[53] Germano R., Ausanio G., Iannotti V., Lanotte L., Luponio C.: Direct magnetostriction and magnetoelastic wave amplitude to measure a linear displacement. Sensors and Actuators A: Physical, 81, 134-136 (2000). https://doi.org/10.1016/S0924-4247(99)00153-3

[54] Ausanio G., Hison C., Iannotti V., Luponio C., Lanotte L.: Magnetoelastic stress and strain sensors. in 'Encyclopedia of sensors' (eds.: Grimes C. A., Dickey E. C., Pishko M. V.) American Scientific Publishers, Santa Clarita, Vol 5, 489-528 (2006).

[55] Grimes C. A., Roy S. C., Rani S., Cai Q.: Theory, instrumentation and applications of magnetoelastic resonance sensors: A review. Sensors, 11, 2809-2844 (2011). https://doi.org/10.3390/s110302809

[56] Guarino V., Cirillo V., Altobelli R., Ambrosio L.: Polymer-based platforms by electric field-assisted techniques for tissue engineering and cancer therapy. Expert Review of Medical Devices, 12, 113-129 (2015). https://doi.org/10.1586/17434440.2014.953058

[57] Guarino V., Altobelli R., Cirillo V., Cummaro A., Ambrosio L.: Additive electrospraying: A route to process electrospun scaffolds for controlled molecular release. Polymers for Advanced Technology, 26, 1359-1369 (2015). https://doi.org/10.1002/pat.3588

[58] Wan Abdul Khodir W. K., Guarino V., Alvarez-Perez M. A., Cafiero C., Ambrosio L.: Trapping tetracyclineloaded nanoparticles into polycaprolactone fiber networks for periodontal regeneration therapy. Journal of Bioactive and Compatible Polymers, 28, 258-273 (2013). https://doi.org/10.1177/0883911513481133

[59] Cirillo V., Clements B. A., Guarino V., Bushman J., Kohn J., Ambrosio L.: A comparison of the performance of mono- and bi-component electrospun conduits in a rat sciatic model. Biomaterials, 35, 8970-8982 (2014). https://doi.org/10.1016/j.biomaterials.2014.07.010

[60] Alippi C.: A unique timely moment for embedding intelligence in applications. CAAI Transactions on Intelligence Technology, 1, 1-3 (2016). https://doi.org/10.1016/j.trit.2016.03.002

[61] Jin H., Chen Q., Chen Z., Hu Y., Zhang J.: Multi-leapmotion sensor based demonstration for robotic refine tabletop object manipulation task. CAAI Transactions on Intelligence Technology, 1, 104-113 (2016).

https://doi.org/10.1016/j.trit.2016.03.010 